\title{
TINGKAT KERUSAKAN MINYAK KELAPA SELAMA PENGGORENGAN VAKUM BERULANG PADA PEMBUATAN RIPE BANANA CHIPS (RBC)
}

Degree of Coconut Oil Rancidity During Recycled Vacuum Frying for Production of Ripe Banana Chips (RBC)

\author{
Herlina Herlina $^{1)} *$, Ely Astriyaningsih ${ }^{1)}$, Wiwik Siti Windarti ${ }^{1)}$, Nurhayati Nurhayati ${ }^{1)}$ \\ ${ }^{1)}$ Jurusan Teknologi Hasil Pertanian - Fakultas Teknologi Pertanian, Universitas Jember \\ Jalan Kalimantan 37 Kampus Tegalboto, Jember 68121 \\ *E-mail: lina.ftp@unej.ac.id
}

\begin{abstract}
Coconut oil is an oil produced from the old coconut that is obtained from the pulp of a coconut in the extract through the manufacture of coconut milk and finally becomes oil. The damage on oils such as oxidation reaction, hydrolysis reaction and polymerization reaction. This study aims to know the extent of coconut oil damage during repeated vacuum frying on the manufacture of Ripe Banana Chips (RBC) by testing the free fatty acids, Iodine Numbers, Peroxide Numbers, Viscosity, Specific Weight and Clarity. Fat Free Acid Content, Iodine Numbers and Peroxide Numbers are determined by iodometric method, viscosity by oswald viscometer method, specific gravity by pycnometer and clarity by spectrophotometer. The sample is coconut oil in each fryer by using a vacuum fryer. Measurement is repeated with three times for each oil. The results showed that average oil free fatty acid analysis was 0,1944\% - 0,2414\%. Iodine ranges from 41,783mg/g-45,7141 mg/g. Peroxide numbers range from $2,5909 \mathrm{mekO} / \mathrm{kg}-3,067 \mathrm{mekO}_{2} / \mathrm{kg}$. The average yield of viscosity analysis ranged from 0,0205Poise-0,0333Poise. Specific gravity ranged from 0,9144 $\mathrm{g} / \mathrm{ml}-0,9193 \mathrm{~g} / \mathrm{ml}$. The average results of clarity analysis ranged from 0,0788-0,0928. The conclusion of this study is the more frequent oil that's used with vacuum frying on the manufacture of Ripe Banana Chips (RBC) can caused the quality of oil is decreased. This is indicated by the increase of free fatty acid content, peroxide number, specific gravity, viscosity and decrease of iodine number and clarity.
\end{abstract}

Keywords: oil rancidity, coconut oil, vacuum frying, ripe banana chips (RBC)

\section{PENDAHULUAN}

Buah-buahan merupakan salah satu komoditas hortikultura yang memiliki nilai ekonomi tinggi dan memiliki peluang untuk diekspor. Produk buah-buahan di Indonesia pada umumnya dikonsumsi dalam bentuk buah segar dan masih sedikit yang diolah ke dalam bentuk makanan olahan salah satunya yaitu buah pisang. Di Indonesia buah pisang memiliki nilai produktivitas yang tinggi yaitu mencapai 7,29 juta ton pada tahun 2015 (Badan Pusat Statistik, 2015) sedangkan buah pisang bersifat mudah rusak (perishable) setelah dipanen, di samping itu tingkat kehilangan hasil cukup tinggi yaitu mencapai 25-40\% (Hasan, 2005). Salah satu alternatif untuk meningkatkan umur simpan serta nilai tambah produk buah pisang adalah dengan melakukan pengolahan buah-buahan menjadi keripik atau bisa disebut Ripe Banana Chips (RBC).

Ripe Banana Chips (RBC) merupakan makanan ringan yang menyehatkan karena kandungan seratnya yang tinggi. Penggorengan Ripe Banana Chips (RBC) dapat dilakukan dengan menggunakan penggorengan pada tekanan vakum. Penggorengan vakum digunakan untuk buah-buahan yang kandungan airnya tinggi misalnya pisang (75\%) (Mulyati, 2005). Berkembangnya teknologi penggorengan vakum menghasilkan Ripe Banana Chips (RBC) yang memiliki rasa dan aroma seperti buah aslinya, tekstur renyah serta nilai gizinya relatif dapat dipertahankan karena proses penggorengan 
berlangsung pada suhu relatif rendah (Enggar, 2009).

Pada kondisi vakum, suhu penggorengan dapat diturunkan menjadi $80-90^{\circ} \mathrm{C}$ karena titik didih minyak mengalami penurunan, sehingga kerusakan warna, aroma, rasa, dan nutrisi pada produk akibat panas dapat dihindari. Kerusakan minyak dan akibat lain yang ditimbulkan karena suhu tinggi dapat diminimalkan karena proses dilakukan pada suhu dan tekanan rendah. Pada proses penggorengan, minyak goreng berfungsi sebagai medium penghantar panas, menambah rasa gurih, menambah nilai gizi dan kalori dalam bahan pangan. Minyak yang dikonsumsi sangat erat kaitannya bagi kesehatan kita. Minyak yang sering kita dengar ada dua macam yaitu minyak sawit dan minyak kelapa.

Masyarakat lebih memilih minyak kelapa sawit karena harganya lebih terjangkau, namun bila ditinjau dari segi kesehatan minyak kelapa lebih menyehatkan dan memiliki banyak keuntungan yakni memberikan keuntungan gizi klinis bagi individu yang tidak dapat menyerap asam lemak rantai panjang. Selain itu minyak kelapa lebih mudah diserap usus dan tidak digabungkan dengan kilomikron untuk diangkut dan disimpan dalam jaringan adipose, tetapi langsung diangkut ke hati untuk dioksidasi menjadi energi yang siap digunakan oleh tubuh (Kennedy, 1991). Oleh karena itu, dalam penelitian ini digunakan minyak kelapa sebagai medium penghantar panas dalam pembuatan Ripe Banana Chips (RBC).

Saat proses penggorengan berlangsung, minyak goreng akan teradsorbsi pada makanan sebanyak 5$40 \%$, dengan demikian minyak goreng juga akan ikut terkonsumsi dan masuk ke dalam tubuh. Hal ini tidak menjadi masalah selama minyak yang digunakan untuk menggoreng tidak rusak, akan tetapi masyarakat kebanyakan tidak mengetahui hal tersebut dan terus menggunakan minyak goreng berkali-kali hingga menjadi rusak (LPPOM, 2010). Penggunaaan minyak goreng yang berulang tersebut menjadi masalah yang ada dalam proses penggorengan (Hartini, 2011).

Minyak yang berulang kali digunakan dapat menyebabkan penurunan mutu bahkan akan menimbulkan bahaya bagi kesehatan. Penggunaan minyak goreng berulang kali akan mengalami berbagai reaksi kimia diantaranya reaksi hidrolisis, oksidasi, isomerisasi dan polimerisasi. Kerusakan tersebut menyebabkan minyak menjadi berwarna kecoklatan, lebih kental, berbusa, berasap, serta meninggalkan odor yang tidak disukai pada makanan. Perubahan akibat pemanasan tersebut antara lain disebabkan oleh terbentuknya senyawa yang bersifat toksik dalam bentuk hidrokarbon, asamasam lemak hidroksi, epoksida, senyawasenyawa siklik, dan senyawa senyawa poplimer (Ketaren, 2008). Penelitian ini dilakukan untuk mengetahui tingkat kerusakan minyak kelapa dalam penggorengan vakum berulang.

Penelitian ini bertujuan untuk mengetahui tingkat kerusakan minyak kelapa selama penggorengan vakum berulang pada pembuatan Ripe Banana Chips (RBC).

\section{METODE PENELITIAN}

\section{Alat dan Bahan}

Alat yang digunakan dalam penelitian ini adalah penggorengan vakum kapasitas produksi $5 \mathrm{~kg}$, buret, spektrofotometer, piknometer, neraca analitik, hot plate, spatula, pipet tetes, gelas kaca, stopwatch dan thermometer.

Bahan-bahan yang digunakan dalam penelitian ini adalah pisang mas pada kematangan level 5-6 (pisang masak dengan kulit kuning merata), minyak kelapa merck DORANG, botol gelap, etanol 96\%, indikator phenopthalin (PP), $\mathrm{NaOH} 0,1 \mathrm{~N}$, aquadest, asam oksalat, 
$\mathrm{Na}_{2} \mathrm{~S}_{2} \mathrm{O}_{3} 0,1 \mathrm{~N}, \mathrm{Na}_{2} \mathrm{CO}_{3}, \mathrm{KIO}_{3}, \mathrm{KI}$ jenuh, $\mathrm{KI} 15 \%, \mathrm{HCl} 2 \mathrm{~N}$, amilum, asam asetat glasial, chloroform, $\mathrm{CHCl}_{3}$, reagen yodium bromida, Yodium dan bromin.

\section{Tahapan Penelitian}

\section{Persiapan bahan baku}

Persiapan alat dan bahan baku meliputi perbaikan dan pengkondisian alat penggorengan vakum, pembelian bahan baku berupa pisang mas kirana dengan tingkat kematangan level 5-6 (pisang masak dengan kulit kuning merata) dan minyak goreng. Perbaikan dan pengkondisian alat penggorengan vakum dilakukan dengan memperbaiki bagian seal dari alat sehingga mendukung proses pemvakuman. Pengkondisian alat dilakukan dengan menghidupkan alat vakum hingga menunjukkan tekanan di atas $-60 \mathrm{cmHg}$ dan penyetelan (setting) kompor untuk beroperasi pada suhu 80$90^{\circ} \mathrm{C}$.

\section{Produksi ripe banana chips $(R B C)$}

Produksi RBC dilakukan dengan lima tahap yaitu pengupasan, pembekuan, penggorengan, pengurangan kadar air, dan pengemasan. Pertama mengupas pisang mas masak tetapi sebelum pisang dikupas pada kedua ujungnya dipotong selanjutnya bagian tengah dilubangi dengan menggunakan pipa plong. Hal ini bertujuan mempertahankan bentuk pisang agar tetap utuh dan adanya lubang membujur di bagian tengah mampu mengoptimalkan transfer panas dari minyak ke bahan (buah pisang).

Tahap selanjutnya adalah

pembekuan buah pisang dengan menggunakan suhu $-10^{\circ} \mathrm{C}$ selama 120 menit. Tahap penggorengan vakum dilakukan pada suhu $80-90^{\circ} \mathrm{C}$ dengan tekanan -70s/d-76 cmHg selama 3 jam. Sebelum kompor dinyalakan, penggoreng vakum diisi dengan minyak goreng nabati sebanyak $60 \mathrm{~kg}$ untuk kapasitas alat $5 \mathrm{~kg}$ bahan baku. Setelah penggorengan, produk RBC diangkat dan dikurangi kadar minyaknya dengan menggunakan teknik sentrifugasi/pemusingan selama 5 menit. Selanjutnya produk siap dikemas dan dilabel.

Perbandingan bahan baku daging buah pisang masak dengan minyak nabati yang digunakan adalah 1:12. Perbandingan ini dapat diperkecil hingga 1:7 dalam rangka efisiensi penggunaan minyak. Akan tetapi dapat meningkatkan mutu produk yang dihasilkan berdasarkan parameter tingkat kerenyahannya. Selama penggorengan dilakukan pengadukan dengan menggoyangkan wadah dalam penggorengan dengan menggunakan tuas. Penggoyangan cukup dilakukan dua kali frekuensi tiap 20-30 menit. Jika terlalu sering digoyang maka dapat merusak penampilan produk (produk ada yang tidak utuh irisannya/patah). Tahap selanjutnya adalah pengurangan kadar minyak produk RBC dengan teknik sentrifugasi menggunakan alat spiner. Produk RBC yang dihasilkan adalah sekitar 26-36\% dari berat awal bahan baku buah pisang yang digunakan (sekitar 1,3-1,8 kg dari $5 \mathrm{~kg}$ daging buah pisang). Tahap terakhir adalah penimbangan, pengemasan dan labeling.

\section{Pengambilan sampel}

Pengambilan sampel sebanyak 200 $\mathrm{ml}$ di setiap penggorengan, penggorengan digunakan sebanyak 4 kali. Sampel yang telah didapat di analisis meliputi kadar asam lemak bebas, bilangan iod, bilangan peroksida, viskositas, berat jenis dan kejernihan.

\section{Rancangan Percobaan}

Penelitian ini menggunakan metode Rancangan Acak Lengkap (RAL) 1 faktor yaitu perlakuan penggorengan dengan 3 kali titik pengukuran. Faktor perlakuan penggorengan terdiri dari 4 taraf yaitu $B_{1}$ : Penggorengan $1, \mathrm{~B}_{2}$ : Penggorengan $2, \mathrm{~B}_{3}$ : Penggorengan 3 dan $B_{4}$ : Penggorengan 4 . Data yang diperoleh dianalisis menggunakan analisis deskriptif. 


\section{Metode Analisis}

Pengujian analisa meliputi uji kimia dan uji fisik. Parameter uji kimia meliputi kadar asam lemak bebas (Sudarmadji et al., 2007), bilangan iod (Sudarmadji et al., 2007) dan bilangan peroksida (SNI, 2013). Pengujian menggunakan metode iodometri. Uji fisik meliputi viskositas metode oswald, berat jenis (Ketaren, 2012) dan Kejernihan (Sudarmadji et al., 2007).

\section{HASIL DAN PEMBAHASAN}

\section{Kadar Asam Lemak Bebas}

Asam lemak bebas merupakan hasil hidrolisis dari trigliserida. Pada saat minyak digunakan, pada awal proses asam lemak bebas dihasilkan melalui proses pemecahan oksidasi. Namun, pada tahap selanjutnya asam lemak bebas dihasilkan dari proses hidrolisis yang disebabkan karena adanya air. Minyak yang digunakan dalam proses penggorengan memiliki resiko besar dalam terbentuknya asam lemak bebas karena adanya perlakuan panas dengan temperatur yang tinggi yang menyebabkan meningkatnya kandungan asam lemak bebas. Hal ini sesuai dengan pernyataan Ketaren (2008), kandungan asam lemak bebas minyak akan meningkat selama pemanasan, disebabkan peristiwa oksidasi dan hidrolisis. Pada proses ini terjadi pemutusan rantai triglesirida menjadi asam-asam lemak bebas dan gliserol. Nilai Kadar Asam Lemak Bebas dapat dilihat pada Gambar 1.

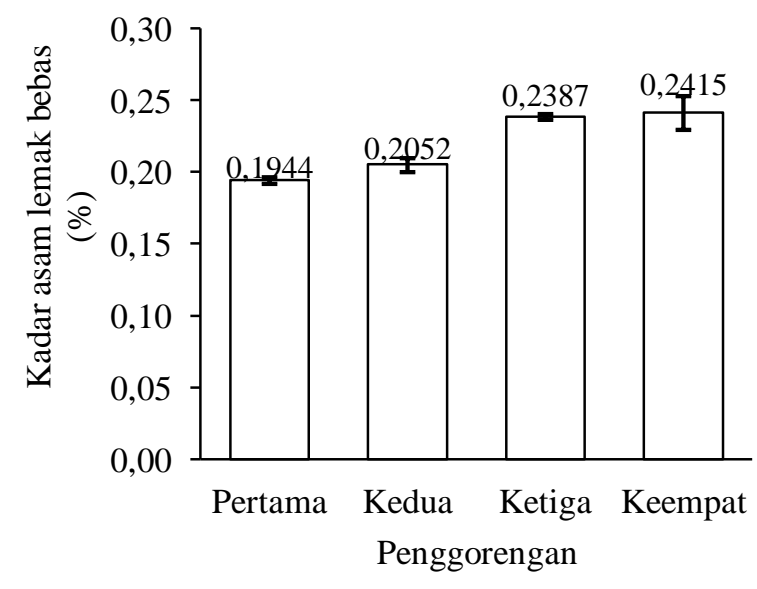

Gambar 1. Nilai kadar asam lemak bebas minyak kelapa penggorengan vakum berulang pada pembuatan RBC

Gambar 1 menunjukkan bahwa minyak dari hasil penggorengan berulang RBC mengalami peningkatan pada kadar asam lemak bebas karena adanya air pada minyak dan panas pada waktu penggorengan sehingga terjadi hidrolisis pada minyak, hal ini sesuai dengan pernyataan Sulieman et al., (2001) bahwa kenaikan kadar asam lemak bebas disebabkan karena pada saat penggorengan pertama, kadar air dalam minyak belum terlalu banyak, tetapi pada proses penggorengan selanjutnya kadar air pada minyak semakin bertambah. Keberadaan air pada minyak yang berasal dari bahan baku yang mempercepat poses hidrolisis dari minyak goreng.

\section{Bilangan Iod}

Bilangan iod ditentukan untuk mengukur jumlah asam lemak tidak jenuh pada minyak dan lemak (Talpur, 2009). Semakin lama penggunaan minyak goreng akan semakin kecil bilangan iodnya. Hasil analisis bilangan iod minyak goreng tertinggi ada pada penggorengan pertama sebesar $45,7141 \mathrm{mg} / \mathrm{g}$ sedangkan bilangan iod terendah ada pada penggorengan keempat sebesar 41,783 mg/g dapat dilihat pada Gambar 2. Hasil keseluruhan menunjukkan bahwa sampel minyak 
goreng terjadi penurunan bilangan iod. Penurunan bilangan iod disebabkan karena adanya dekomposisi pada minyak goreng dan penjenuhan ikatan rangkap yang melalui degradasi hidroperoksida membentuk produk sekunder berupa asam karboksilat, karbonil dan senyawa hasil degradasi yang lain (Farida et al., 2006).

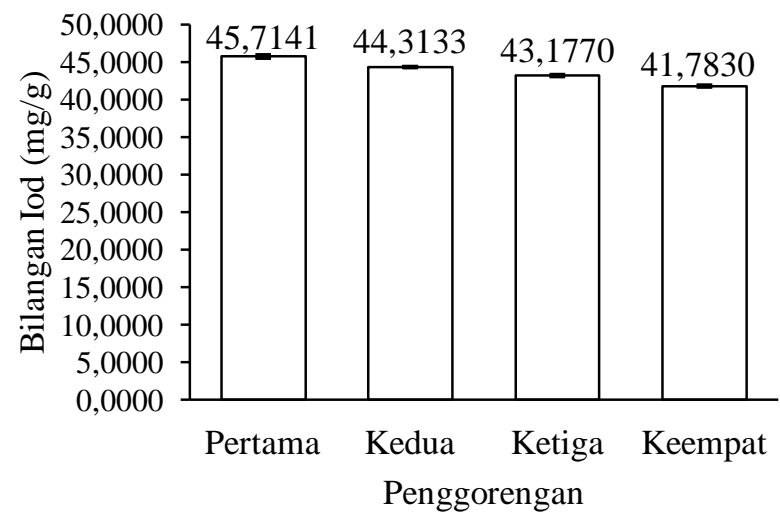

Gambar 2. Nilai bilangan iod minyak kelapa penggorengan vakum berulang pada pembuatan RBC

Gambar 2 menunjukkan bahwa bilangan iod mengalami penurunan. Perubahan bilangan iod masing-masing sampel setelah setiap kali penggorengan berbeda-beda. Apabila bilangan iod rendah maka tingkat ketidakjenuhannya juga rendah. Tingginya tingkat ketidakjenuhan minyak menyebabkan minyak semakin mudah teroksidasi. Apabila minyak mudah teroksidasi maka tingkat ketidakjenuhannya semakin berkurang karena ikatan rangkapnya sudah putus sehingga bilangan iodnya semakin kecil (Tyas, 2011).

\section{Bilangan Peroksida}

Bilangan peroksida dapat diukur secara kuantitatif dengan menggunakan titrasi iodometri dengan penentuan jumlah iodin yang dibebaskan menggunakan kalium iodida. Iodin yang telah dibebaskan dititrasi dengan natrium tiosulfat, selanjutnya ditambahkan indikator amilum hingga berwarna biru, kemudian ditirasi kembali dengan natrium tiosulfat hingga warna biru tepat menghilang. Nilai Bilangan Peroksida dapat dilihat pada Gambar 3.

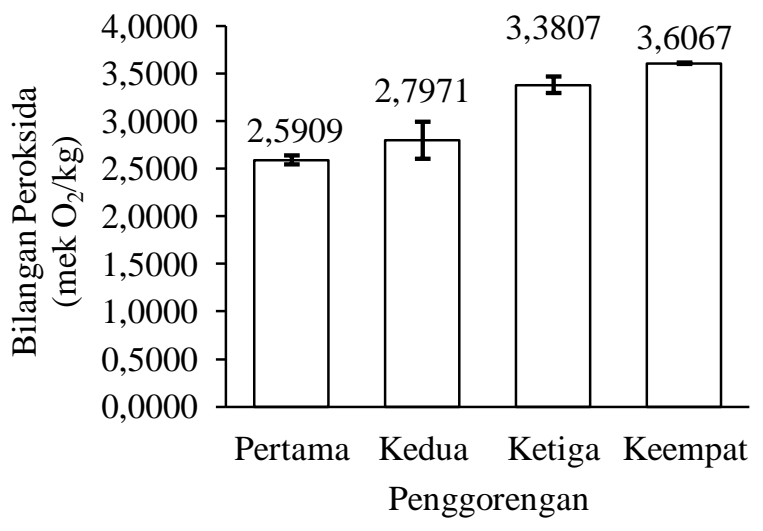

Gambar 3. Nilai bilangan peroksida minyak kelapa penggorengan vakum berulang pada pembuatan RBC

Gambar 3 menunjukkan hasil ratarata analisis bilangan peroksida minyak pada penggorengan vakum berkisar antara 2,5909 mek $\mathrm{O}_{2} / \mathrm{kg}$ - 3,067 mek $\mathrm{O}_{2} / \mathrm{kg}$, secara keseluruhan bilangan peroksida masih dalam standar yang ditetapkan oleh SNI 01-3741-2013 yaitu maksimal 10 mek $\mathrm{O}_{2} / \mathrm{kg}$.

Proses oksidasi lemak berpengaruh terhadap mutu produk-produk makanan yang dihasilkan, kerusakan minyak dikarenakan adanya reaksi yang melibatkan oksigen yang dikenal dengan ketengikan. Peroksida terbentuk pada tahap inisiasi oksidasi, pada tahap ini hidrogen akan menghasilkan radikal bebas. Radikal bebas yang terbentuk bereaksi dengan oksigen membentuk radikal peroksi, selanjutnya atom hidrogen dari molekul tak jenuh lain menghasilkan peroksida dan radikal bebas yang baru (Aminah, 2010). Umumnya kerusakan oksidasi terjadi pada asam lemak tidak jenuh, tetapi bila minyak dipanaskan pada suhu $100^{\circ} \mathrm{C}$ atau lebih, asam lemak jenuh pun akan teroksidasi.

\section{Viskositas}

Viskositas adalah suatu sifat yang menentukan besarnya daya tahan terhadap 
gaya geser atau dapat didefinisikan sebagai ketahanan terhadap aliran. Viskositas dari suatu fluida dihubungkan dengan tahanan terhadap gaya yang menggeserkan fluida pada lapisan yang satu dengan yang lain. Hasil rata-rata analisis viskositas minyak pada penggorengan vakum berkisar antara 0,0205 Poise - 0,0333 Poise dapat dilihat pada Gambar 4. yang menunjukkan bahwa viskositas semakin meningkat disetiap penggorengan.

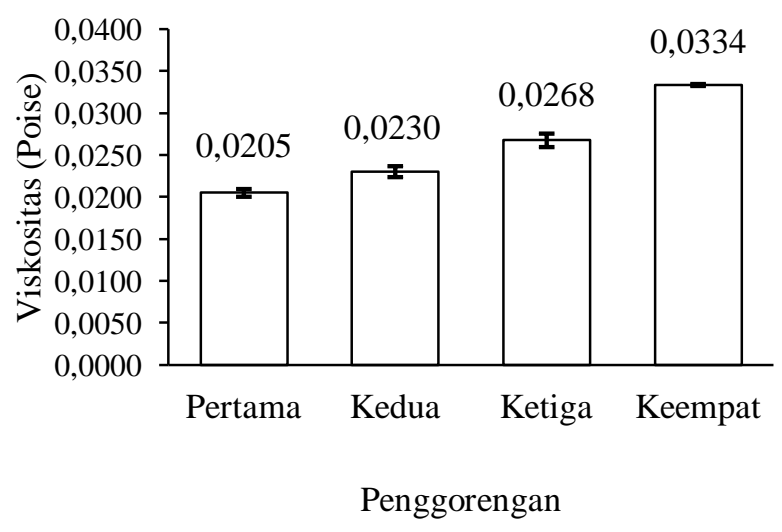

Gambar 4. Nilai viskositas minyak kelapa penggorengan vakum berulang pada pembuatan RBC

Gambar 4 menunjukkan nilai viskositas mengalami peningkatan. Peningkatan viskositas pada minyak diakibatkan karena minyak memiliki konsentrasi padatan terlarut yang tinggi yang menyebabkan viskositas juga semakin tinggi. Padatan terlarut berasal dari padatan yang digoreng. Semakin banyak partikel yang terlarut, gesekan antar partikel semakin tinggi dan viskositasnya semakin tinggi pula (Sani, 2010). Selain karena zat terlarut, viskositas juga dipengaruhi oleh adanya reaksi polimerisasi yang berlangsung selama penggorengan. Reaksi polimerisasi disebabkan oleh suhu dan pemanasan yang lama (Salamah, 2007). Ketika minyak dipanaskan pada suhu ekstrim dalam waktu yang lama akan terbentuk molekul besar yang disebut polimer. Ketika polimer telah terbentuk dalam jumlah yang cukup banyak, maka viskositas dari minyak akan meningkat. Menurut Febriansyah (2007), polimer merupakan senyawa yang terbentuk di dalam minyak goreng akibat pemanasan terus menerus pada suhu tinggi dengan atau tanpa adanya oksigen.

\section{Berat Jenis}

Uji densitas atau berat jenis adalah pegujian yang bertujuan untuk mengetahui berat jenis dari sampel, dimana dalam hal ini minyak kelapa yang digunakan sebagai sampel. Penelitian ini untuk menunjang keberhasilan uji berat jenis, dilakukan pengujian dengan menggunakan alat piknometer. Prinsip metode ini didasarkan atas penentuan massa cairan dan penentuan ruang, yang ditempati cairan ini, dibutuhkan wadah untuk menimbang yang dinamakan piknometer (Ahmad, dkk.,2014).

Hasil rata-rata analisis berat jenis minyak pada penggorengan vakum berkisar antara $0,9144 \mathrm{~g} / \mathrm{ml}-0,9193 \mathrm{~g} / \mathrm{ml}$ dapat dilihat pada Gambar 5 yang menunjukkan bahwa berat jenis semakin meningkat disetiap penggorengan.

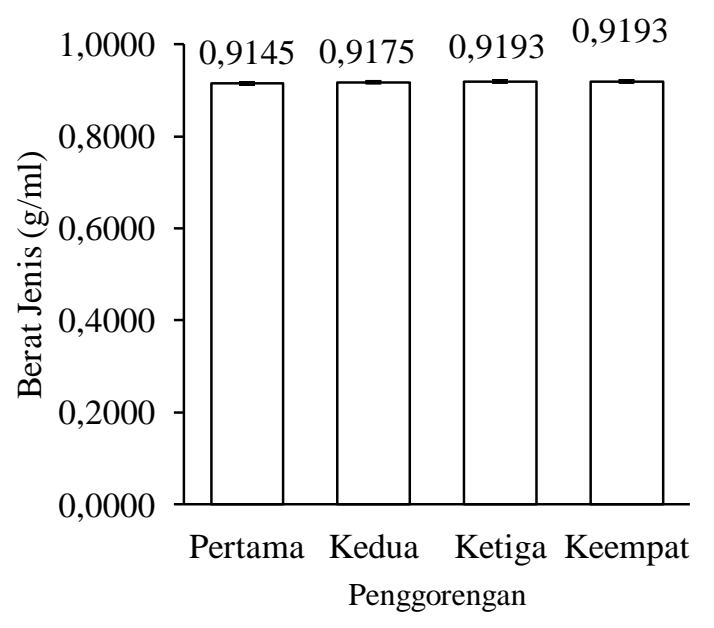

Gambar 5. Nilai berat jenis minyak kelapa penggorengan vakum berulang pada pembuatan RBC

Gambar 5 menunjukkan bahwa berat jenis dipengaruhi oleh viskositas, 
massa zat dan padatan terlarut (Sani, 2010). Viskositas suatu zat dapat mempengaruhi berat jenisnya karena viskositas berbanding lurus dengan berat jenis. Jadi semakin besar viskositas suatu zat maka semakin besar pula berat jenisnya. Massa zat juga mempengaruhi massa jenis karena jika zat mempunyai massa yang besar maka kemungkinan bobot jenisnya juga menjadi lebih besar. Padatan terlarut juga mempengaruhi berat jenis karena banyak partikel yang terlarut, gesekan antar partikel semakin tinggi dan viskositasnya semakin tinggi pula (Sani, 2010). Nilai tertinggi yang didapatkan sebesar 0,9193 g/ml. Menurut SNI 37411995 berat jenis maksimal 0,921 g/ml.

\section{Kejernihan}

Kejernihan telah dijadikan sebagai indeks kualitas minyak selama bertahuntahun. Metode pengujian dilakukan dengan menggunakan spektrofotometer pada panjang gelombang $470 \mathrm{~nm}$. Absorbansi yang semakin besar pada panjang gelombang mengindikasikan kejernihan minyak semakin rendah. Hal ini berarti semakin banyak produk-produk hasil degradasi minyak (Przybylski, 2000). Kejernihan minyak pada penggorengan vakum berkisar antara 0,0788 - 0,0928 dapat dilihat pada Gambar 6. yang menunjukkan bahwa absorbansi semakin meningkat di setiap penggorengan.

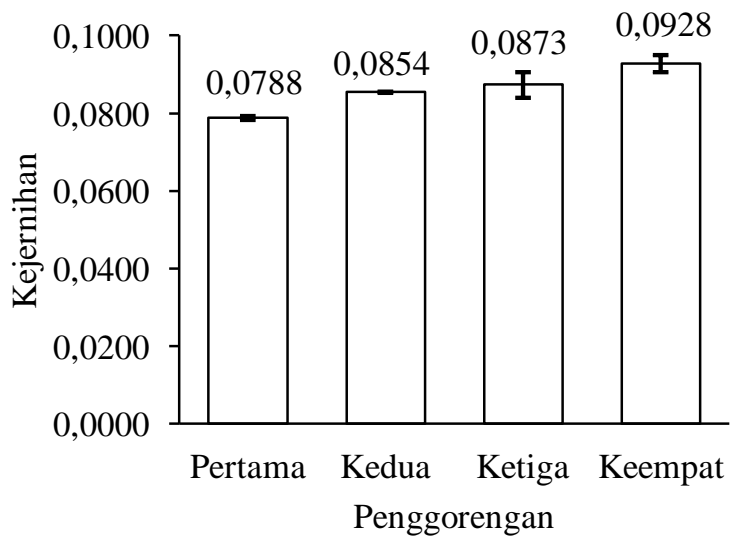

Gambar 6. Nilai kejernihan minyak kelapa penggorengan vakum berulang pada pembuatan RBC
Kejernihan pada minyak pada setiap kali penggorengan mengalami penurunan. Penurunan ini disebabkan oleh senyawa hasil oksidasi asam lemak tak jenuh pada pemasakan suhu tinggi serta penggunaan secara berulang-ulang. Selain oksidasi yang terjadi kejernihan juga dipengaruhi oleh zat terlarut didalamnya, semakin banyaknya partikel yang terlarut, gesekan antar partikel semakin tinggi (Sani, 2010). Ketika minyak dipanaskan pada suhu ekstrim dalam waktu yang lama akan terbentuk molekul besar yang disebut polimer. Menurut Febriansyah (2007), polimer merupakan senyawa yang terbentuk di dalam minyak goreng akibat pemanasan terus menerus pada suhu tinggi dengan atau tanpa adanya oksigen.

\section{KESIMPULAN}

Semakin banyak frekuensi penggunaan minyak dengan penggorengan vakum pada pembuatan Ripe Banana Chips (RBC) menyebabkan kualitas minyak semakin menurun, hal ini ditandai dengan meningkatnya kadar asam lemak bebas, bilangan peroksida, berat jenis, viskositas serta menurunnya bilangan iod dan kejernihannya. Nilai kadar asam lemak bebas $0,1944 \%, 0,2052 \%, 0,2387 \%$, $0,2415 \%$; bilangan iod $45,7141 \mathrm{mg} / \mathrm{g}$, $44,3133 \mathrm{mg} / \mathrm{g}, \quad 43,1770 \mathrm{mg} / \mathrm{g}, \quad 41,7830$ $\mathrm{mg} / \mathrm{g}$; bilangan peroksida 2,5909 mek $\mathrm{O}_{2} / \mathrm{kg}, 2,7971$ mek $\mathrm{O}_{2} / \mathrm{kg}, 3,3807$ mek $\mathrm{O}_{2} / \mathrm{kg}, 3,6067$ mek $\mathrm{O}_{2} / \mathrm{kg} ;$ Viskositas 0,0205 Poise, 0,0230 Poise, 0,0268 Poise, 0,0334 Poise; Berat Jenis 0,9145 g/ml, $0,9175 \mathrm{~g} / \mathrm{ml}, 0,9193 \mathrm{~g} / \mathrm{ml}, 0,9193 \mathrm{~g} / \mathrm{ml}$ dan kejernihan 0,0788, 0,0854, 0,0873, 0,0928.

\section{UCAPAN TERIMA KASIH}

Ucapan terima kasih kepada Dirjen Inovasi Kemristekdikti yang telah mensupport penelitian ini melalui program CPPBT Tahun 2016 atas nama Dr. Nurhayati, S.TP, M.Si. 


\section{DAFTAR PUSTAKA}

Sani, A, Masyhuri Machfudz. 2010. 2010. Metodologi Riset Manajemen Sumber Daya Manusia. Cetakan Pertama. Maliki Press, UIN-Malang.

Ahmad, Dedi, Putri Nopita S dan Purwa Gilang R. 2014. "Uji Kualitas Minyak Kelapa Dengan Uji Coba Penggorengan". Program Studi Teknologi Agroindustri Fakultas Pendidikan Teknik dan Kejuruan Universitas Pedidikan Indonesia, Bandung.

Aminah, S. 2010. Bilangan Peroksida Minyak Goreng Curah Dan SifatOrganoleptik Tempe Pada

Pengulangan Penggorengan. Jurnal Pangandan Gizi Universitas Muhammadiyah Semarang, 1 (1): 7-14.

Badan Pusat Statistik. 2015. Data Produksi Padi, Jagung, dan Kedelai Provinsi Lampung tahun 2014. Berita Resmi Statistik. Lampung.

Enggar. 2009. Prinsip kerja alat penggorengan vakum. Jurnal Agrikultura, 12 (6): .

Farida, Y dan Siregar, I. F. 2009. Pengaruh pemanasan berulang terhadap sifat fisikokimia dan kandungan asam palmitat pada minyak goreng. Jurnal Ilmu Kefarmasian Indonesia, pp: 83-91.

Febriansyah, R. 2007. "Mempelajari Pengaruh Penggunaan Berulang dan Aplikasi Adsorben Terhadap Kualitas Minyak dan Tingkat Penyerapan Minyak Pada Kacang Sulut". Skripsi. Fakultas Teknologi Pertanian Institut Pertanian Bogor, Bogor.

Hartini, S. 2011. Evaluasi Pembelajaran. Qinant, Surakarta.

Ketaren, 2008.Minyak dan Lemak Pangan. UI Press, Jakarta.

Kennedy, K. 1991. National, state, and local planning. In Teaching Social Studies (Scond Edition) by Colin Marsh (editor). Pritice Hall, Ney York.
LPPOM. 2010. Tidak Thoyyib, Menggunakan Minyak jelantah Berulang - Ulang. Jurnal lppom mui.www.halalmui.org. Jakarta.

Mulyati, S. 2005. Aneka Olahan Pisang. Trubus Angisana, Surabaya.

Przybylski, R. 2000. Effect of Oils and Fats Composition on Their Frying Performance. $\quad$ www.gov.mb.ca. [Diakses Tanggal 3 Agustus 2007]

Hasan, R. 2005. Buku Kuliah 2 Ilmu Kesehatan Anak. Balai Penerbit FKUI, Jakarta.

Salamah, U. (2007). Hubungan Kualitas Minyak Goreng yang Digunakan secara Berulang Terhadap Umur Simpan Keripik Sosis Ayam. http://repository.ipb.ac.id/handle/12345 6789/10454 [Diakses Tanggal 23 Juli 2017).

SNI. 2013. Minyak Goreng. BSN (Badan Standarisasi Nasional), Jakarta.

Sudarmadji. S., Haryono, B., Suhardi. 2007. Analisis bahan makanan dan pertanian. Liberty, Yogyakarta.

Sulieman M, Abd El-Rahman, Attya ElMakhzangy, dan Mohamed Fawzy Ramadan 2001. Antiradikal performance and physicochemical characteristics of vegetable oils upon frying of french fries: a preliminary comparative. Journal of Environmental, Agricultural and Food Chemistry.

Talpur. M. Y. 2009. Effects of frying on soy bean, sun flower, and canola oils. Journal Analysis Environment Chemical, 10: 59.

Tiyas, N. D. 2011. Analisis Penurunan Bilangan Iod Terhadap Pengulangan Penggorengan Minyak Kelapa Dengan Metode Titrasi Iodometri. Fakultas Tarbiyah dan Keguruan Universitas Islam Negeri Sultan Syarif Kasim Riau, Pekanbaru, Pekanbaru. 